\title{
Quality of life of a person with Parkinson's disease and the relationship between the time of evolution and the severity of the disease
}

\author{
Fabiana Magalhães Navarro-Peternella ${ }^{1}$
}

Sonia Silva Marcon²

Parkinson's disease can cause disability and decrease the quality of life in its sufferers. The aim of this study was to evaluate the quality of life of a group of people with Parkinson's disease and whether a relationship exists between time of evolution and severity of the disease. Secondary analysis was carried out on transversal data collected from 40 individuals with Parkinson's disease registered in the Parkinson's Association of Maringá, in MaringáPR-Brazil. Measures: three instruments were applied: a socio-demographic questionnaire, the Hoenh and Yahr Scale and the Parkinson's Disease Questionnaire (PDQ-39). According to PDQ-39, men referred to a lower quality of life, although, statistically, there was no significant difference between the two genders. Differences were only observed in the dimensions of "activities of daily living" and "social support", in which men presented higher impairment, and "emotions" and "bodily discomfort", where women showed higher impairment. Furthermore, severity of disease tended to lead to a perception of lower quality of life regarding the dimensions of "activities of daily living" and "cognition", which is relevant to improve clinical guidance and intervention.

Descriptors: Parkinson's Disease; Chronic Disease; Quality of Life.

\footnotetext{
${ }^{1}$ MSc, Unidade de Ensino Superior Ingá, Universidade de Maringá, Brazil.

${ }^{2}$ Free lecturer, Associate Professor, Centro de Ciências da Saúde, Universidade Estadual de Maringá, Brazil.
}

Corresponding Author:

Fabiana Magalhães Navarro-Peternella

Av. Colombo, 9727, km 130

Jardim Industrial

CEP: 87070-810, Maringá, PR, Brasil

E-mail: navarrofabiana@gmail.com 


\title{
Qualidade de vida de indivíduos com Parkinson e sua relação com tempo de evolução e gravidade da doença
}

A doença de Parkinson pode ser incapacitante e prejudicar a qualidade de vida de seus portadores. O objetivo do estudo foi avaliar a qualidade de vida de indivíduos com Parkinson e identificar relações com o tempo de evolução e gravidade da doença. Os dados foram coletados na cidade de Maringá, PR, Brasil, com 40 indivíduos cadastrados na Associação Maringaense de Parkinson, por meio da aplicação de três instrumentos: questionário sociodemográfico, escala de Hoenh e Yahr e PDQ-39. De acordo com o PDQ-39, os homens referiram pior qualidade de vida, embora sem diferenças estatísticas entre os sexos. Diferenças foram observadas apenas na dimensão "atividades de vida diária" e "apoio social", com os homens apresentando maior acometimento e "bem-estar emocional" e "desconforto corporal", com maior comprometimento entre as mulheres. Por outro lado, a gravidade da doença apresentou tendência a pior percepção na qualidade de vida nas dimensões atividades de vida diária e cognição, pontos relevantes para melhor orientação clínica e intervenção.

Descritores: Doença de Parkinson; Doença Crônica; Qualidade de Vida.

\section{Calidad de vida de las personas con enfermedad de Parkinson y su relación con la evolución en el tiempo y la gravedad de la enfermedad}

\begin{abstract}
La enfermedad de Parkinson puede llegar a ser incapacitante y afectar a la calidad de vida de los pacientes. El objetivo de este estudio fue evaluar la calidad de vida de las personas con Parkinson e identificar las relaciones con el transcurso del tiempo y la gravedad de la enfermedad. Los datos fueron recogidos en la ciudad de Maringá-PRBrasil, con 40 personas indexadas en la "Associação Maringaense de Parkinson", a través de la aplicación de tres instrumentos: cuestionario sociodemográfico, escala de Hoenh e Yahr y PDQ-39. De acuerdo con el PDQ-39, los hombres reportaron peor calidad de vida, aunque no hubo diferencias estadísticas entre los sexos. Las diferencias apenas se observaron en la dimensión "actividades de vida diaria" y "apoyo social", con los hombres presentando una mayor participación y "bienestar emocional" e "incomodidad física" con una más grave entre las mujeres. Por otra parte, la gravedad de la enfermedad mostró una tendencia a empeorar la percepción en la calidad de vida en las dimensiones de las actividades de la vida diaria y cognición, puntos importantes para una mejor orientación e intervención clínica.
\end{abstract}

Descriptores: Enfermedad de Parkinson; Enfermedad Cronica; Calidad de Vida.

\section{Introduction}

Parkinson's disease (PD) is the second most prevalent neurodegenerative disease among the elderly, affecting 1 to $3 \%$ of this population ${ }^{(1-2)}$. In Brazil, a study conducted in the state of Minas Gerais found that 3.3\% of individuals over 65 years of age presented $\mathrm{PD}^{(3)}$. Due to its progressive and chronic characteristics, the disease affects the quality of life (QoL) of patients. At the onset of the disease, the physical dimensions seem to be the most affected, since, initially, there are motor symptoms. However, as the disease progresses, there is a development of alterations involving other dimensions www.eerp.usp.br/rlae related to the quality of life ${ }^{(4)}$. This takes place because the evolution of the disease causes an increase in limitations to perform activities of daily living $(A D L)^{(1,5)}$ combined with the appearance of cognitive dysfunction and bodily disorders, increasing the impact on the QoL, and including physical, psychological, emotional, social and economic aspects ${ }^{(2,6-7)}$. Individuals with a chronic illness, such as Parkinson's disease, must deal with physical discomfort as well as loss of social relationships, financial activities, work and leisure ${ }^{(8)}$. 
Health related quality of life in patients with Parkinson's disease is of key importance as new biopsychosocial models of medicine are adopted(9). The majority of PD studies focus on physical impairment and medication effects, aiming to obtain subsidies to improve the planning of therapeutic interventions directed toward these individuals ${ }^{(7,10)}$, considering that the aim of therapy in patients with incurable chronic disorders, such as Parkinson's disease, is to improve their quality of life(11).

However, neuropsychiatric complications that include depression, anxiety, cognitive impairment and psychosis are very common ${ }^{(12)}$. All these factors influence the quality of life of the PD patient, so that they have an individual perception of their real chronic health condition and how it impacts on their quality of life ${ }^{(13)}$. Therefore, the length time living with the disease may or may not predict the degree of impairment in the quality of life of the PD patient.

It is important to identify those factors that most influence the quality of life of the PD patient, considering that these issues may not be evident upon clinical examination, not being part of the more common motor symptoms ${ }^{(9)}$. Therefore, investigating the quality of life becomes crucial in order to understand the course of the disease and to seek strategies to promote the physical and psychic well-being of these individuals, thus improving the planning of therapeutic intervention directed toward them. Understanding these factors contributes to the knowledge and increases the commitment to quality of life which can better target the practice of nursing and of other professionals who work directly with patients and their families.

Considering the above, this study aimed to evaluate the quality of life of individuals with PD and to identify whether a relationship exists between time of evolution and the disease severity.

\section{Method}

Data were collected from March to June of 2008, in the city of Maringá - Paraná - Brazil, with Parkinson patients enrolled at the Parkinson's Association of Maringá (PAM). This association is a civil, non-profit institution, created in 2004, the aim of which is to bring together and offer support to PD patients and their families. Monthly talks are given by Health
Professionals, free speech therapy and physiotherapy is offered, along with other physical activities. Currently, the association has 50 PD patients enrolled, 40 of whom live in Maringá and the others in neighboring cities. The inclusion criteria defined for this study were: to be a PD patient, enrolled in PAM and living in Maringá. The exclusion criterion was: to present another neurodegenerative related disease (dementia, neuropathies, among others). None of the individuals living in Maringá presented neurodegenerative related disease and, therefore, all 40 were included in the study.

The study participants were evaluated individually, using three instruments:

1) a socio-demographic questionnaire, to collect data such as gender, age, ethnology, marital status, education level, time since diagnosis, disease progression time, current symptoms, presence of comorbities, and medication used for the treatment of PD, classified as dopamine, dopamine plus another anti-Parkinson drug and an anti-Parkinson drug only.

2) the Hoenh and Yahr(14) Scale, which measures the severity of the disease according to the signs and symptoms presented. The researcher applies this scale from the observation of the eight stage clinical picture: 0 (zero) for no sign of the disease; 1 for unilateral disease only; 1.5 for unilateral and axial impairment; 2 for bilateral disease, without impairment of equilibrium; 2.5 for bilateral disease with mild impairment of equilibrium; 3 for bilateral disease with mild and moderate impairment of equilibrium; 4 for severe disability, though capable of standing and walking without help and 5 for individuals in a wheelchair or confined to bed, in need of full help. For this study, the stages were grouped into three levels of impairment, defined as mild (0-2.0), moderate (2.53.0) and severe $(3.0-4.0)^{(15)}$.

3) PDQ-39 (Parkinson's Disease Quality of Life Questionnaire) which is a specific questionnaire to measure the perception of quality of life of individuals with $\mathrm{PD}^{(16)}$. It contains 39 questions divided into eight dimensions: mobility, activities of daily living, emotions, stigma, social support, cognition, communication and bodily discomfort. The questions refer to the frequency in which individuals have encountered difficult situations during the previous month, which is graded, by the interviewee, with scores from 0 (never) to 4 (always).

The overall score value or that of each dimension was obtained by using the following calculation:

sum of scores of each question within the dimension

4 (maximum score per question) $\mathrm{X} \mathrm{n}^{\circ}$ of questions within the dimension 
The score is a value from 0 to $100 \%$, with the higher final score equating to the individual having a lower perception of his/her quality of life ${ }^{(5)}$.

Data were organized in an Excel 2003 spreadsheet and analyzed using SPSS (Statistical Package for the Social Sciences), version 13.0 for Windows. According to the Kolmogorov-Smirnov test, all the variables presented normal distribution, except for the Hohen and Yahr Scale and the social support dimension of the PDQ39. For the evaluation of the hypothesis of difference among groups, the Student's t test was used for the normally distributed variables, in order to compare the two independent groups and the ANOVA, following Bonferroni's ad hoc test for multiple comparisons. However, for the variables that did not present normal distribution, the Mann-Whitney test was used in order to compare two independent groups, using $p<0.05$. The statistical descriptive analysis involved measures of central and dispersive tendencies (mean, median and standard deviation), for age, time since diagnosis, disease progression time and, if pertinent, the absolute and percentual frequencies.

The development of the study followed ethical principles according to resolution No. 196/96, of the National Health Council, and the project was approved by the Human Research Ethics Committee of Maringá State University (Protocol No. 438/2007). All the participants signed two copies of the Terms of Free Prior Informed Consent.

\section{Results}

The sample consisted of 40 individuals with PD, the majority of whom were men (25) who presented a mean age of $65.1 \pm 9.9$ years, being lower than the mean age of the women (66.0 \pm 11.6 years). The mean age at which participants received the diagnosis was $57.2 \pm 11.7$ years, and the mean time of disease progression was $8.4 \pm 3.7$ years. Most of the study participants were married (30), white (32), with low levels of education - primary school (23), presented a moderate degree of disease impairment (28) and made use of dopamine (26). Details of clinical and socio-demographic characteristics are shown in Table 1.
Table 1 - Clinical and socio-demographic characteristics of the study participants. Maringá, PR, Brazil, 2008

\begin{tabular}{|c|c|c|}
\hline Variable & n & $\%$ \\
\hline \multicolumn{3}{|l|}{ Gender } \\
\hline Male & 25 & 62.5 \\
\hline Female & 15 & 37.5 \\
\hline \multicolumn{3}{|l|}{ Ethnology } \\
\hline White & 32 & 80.0 \\
\hline Black & 5 & 12.5 \\
\hline Oriental & 3 & 7.5 \\
\hline \multicolumn{3}{|l|}{ Marital Status } \\
\hline Married & 30 & 75.0 \\
\hline Divorced & 2 & 5.0 \\
\hline Widowed & 7 & 17.5 \\
\hline Single & 1 & 2.5 \\
\hline \multicolumn{3}{|l|}{ Education level } \\
\hline Incomplete Primary Education & 22 & 55.0 \\
\hline Complete Primary Education & 1 & 2.5 \\
\hline Incomplete High School Education & 4 & 10.0 \\
\hline Complete High School Education & 5 & 12.5 \\
\hline Incomplete Higher Education & 1 & 2.5 \\
\hline Complete Higher Education & 4 & 10.0 \\
\hline Illiterate & 3 & 7.5 \\
\hline \multicolumn{3}{|l|}{ Disease impairment } \\
\hline Mild $(0-2)$ & 9 & 22.5 \\
\hline Moderate $(2.5-3)$ & 28 & 70.0 \\
\hline Severe $(4-5)$ & 3 & 7.5 \\
\hline \multicolumn{3}{|l|}{ Medication } \\
\hline Dopamine & 5 & 12.5 \\
\hline Dopamine + another anti-Parkinson drug & 21 & 52.5 \\
\hline Another anti-Parkinson drug & 13 & 32.5 \\
\hline No treatment & 1 & 2.5 \\
\hline
\end{tabular}

Among the current signs and symptoms, bradykinesia was the most frequent and was referred to by 37 of the PD patients, followed by tremor and posture instability (35), and rigidity (29). Tremor may not have been the most prevalent symptom at the time, however, it was the first manifestation of the disease identified in the majority of cases (27). Other initial symptoms referred to by patients were slowness in ADL and in walking (7), fatigue and muscular weakness (4), and rigidity and lack of equilibrium (2).

In comparing the two groups of male and female PD patients, although the male patients were found to be younger than the female patients, progression time and severity of the disease were higher in men. This relationship, however, was not statistically confirmed. Statistical differences were observed in only four 
dimensions, with men being more affected in ADL and social support, while women were more affected in relation to emotions and bodily discomfort (Table 2 ).

Table 2 - Comparison between male and female PD patients, according to age, progression time, disease severity, PDQ-39 total score and dimension scores, Maringá, PR, Brazil, 2008

\begin{tabular}{lccc} 
& $\begin{array}{c}\text { Men } \\
\mathbf{n = 2 5} \\
\text { Mean scores } \\
\text { (SD) }\end{array}$ & $\begin{array}{c}\text { Women } \\
\mathbf{n = 1 5} \\
\text { Mean scores } \\
\text { (SD) }\end{array}$ & p value \\
\hline Age & $65.1 \pm 9.9$ & $66.0 \pm 11.6$ & 0.786 \\
Progression time & $8.8 \pm 3.7$ & $7.7 \pm 3.4$ & 0.378 \\
Hoehn and Yahr & $2.7 \pm 0.6$ & $2.3 \pm 0.7$ & 0.151 \\
Total PDQ-39 & $35.9 \pm 12.4$ & $34.7 \pm 17.8$ & 0.808 \\
Mobility & $40.3 \pm 25.8$ & $33.8 \pm 26.7$ & 0.460 \\
ADL & $46.8 \pm 22.3$ & $31.6 \pm 23.2$ & $0.048^{*}$ \\
Emotions & $31.6 \pm 19.3$ & $50.5 \pm 26.9$ & $0.014^{*}$ \\
Stigma & $28.7 \pm 30.8$ & $27.5 \pm 33.8$ & 0.905 \\
Social support & $12.1 \pm 12.0$ & $4.7 \pm 7.8$ & $0.035^{*}$ \\
Cognition & $38.3 \pm 24.9$ & $28.8 \pm 22.0$ & 0.234 \\
Communication & $45.0 \pm 24.8$ & $29.4 \pm 32.5$ & 0.097 \\
Bodily discomfort & $33.6 \pm 17.5$ & $54.4 \pm 29.8$ & $0.008^{*}$ \\
\hline
\end{tabular}

SD - standard deviation

$* p<0.05$

In Table 3, the mean scores for the PDQ-39 dimensions were evaluated according to the different stages of the disease. This data shows that the quality of life of the PD individual is not affected by the stage of the disease and that the only dimensions affected by this variable are mobility, where the differences between the mild and severe groups were significant; and ADL and cognition, where the differences between the mild and severe groups were significant, as well as between those of moderate and severe impairment, which indicates a tendency for these aspects to worsen as the disease severity increases.

Table 3 - Comparison between PD patients of mild, moderate and severe impairment groups, according to the PDQ-39 and its dimensions. Maringá, PR, Brazil, 2008

\begin{tabular}{lcccc}
\hline & $\begin{array}{c}\text { Mild } \\
\mathbf{n = 9} \\
\begin{array}{l}\text { Mean score } \\
\text { (SD) }\end{array}\end{array}$ & $\begin{array}{c}\text { Moderate } \\
\mathbf{n = 2 8} \\
\text { Mean score } \\
(\mathbf{S D})\end{array}$ & $\begin{array}{c}\text { Severe } \\
\mathbf{n = 3} \\
\text { Mean Score } \\
\text { (SD) }\end{array}$ & $\begin{array}{c}\mathbf{p} \text { value } \\
\mathbf{F} \text { test }\end{array}$ \\
\hline PDQ-39 & $30.1 \pm 14.2$ & $35.5 \pm 14.0$ & $51.5 \pm 9.6$ & 0.084 \\
Mobility & $23.6 \pm 20.7$ & $39.2 \pm 23.7$ & $75.8 \pm 22.5$ & $0.004^{*}$ \\
ADL & $22.4 \pm 18.1$ & $41.7 \pm 19.7$ & $76.3 \pm 20.9$ & $0.005^{\star *}$ \\
Emotions & $39.0 \pm 25.2$ & $37.1 \pm 24.9$ & $23.6 \pm 12.7$ & 0.228 \\
Stigma & $19.5 \pm 25.5$ & $30.8 \pm 31.4$ & $4.1 \pm 7.2$ & 0.392
\end{tabular}

Table 3 - (continuation)

\begin{tabular}{|c|c|c|c|c|}
\hline & $\begin{array}{c}\text { Mild } \\
\mathrm{n}=9 \\
\text { Mean score } \\
\text { (SD) }\end{array}$ & $\begin{array}{c}\text { Moderate } \\
n=28 \\
\text { Mean score } \\
\text { (SD) }\end{array}$ & $\begin{array}{c}\text { Severe } \\
n=3 \\
\text { Mean Score } \\
\text { (SD) }\end{array}$ & $\begin{array}{c}p \text { value } \\
F \text { test }\end{array}$ \\
\hline Social support & $16.6 \pm 26.3$ & $8.8 \pm 10.2$ & $12.5 \pm 12.5$ & 0.841 \\
\hline Cognition & $30.4 \pm 23.2$ & $30.5 \pm 21.0$ & $83.3 \pm 3.6$ & $0.000^{*+}$ \\
\hline Communication & $29.1 \pm 26.7$ & $42.0 \pm 28.8$ & $58.3 \pm 8.3$ & 0.127 \\
\hline Bodily discomfort & $42.7 \pm 30.3$ & $40.8 \pm 25.7$ & $33.3 \pm 22.4$ & 0.720 \\
\hline
\end{tabular}

SD - standard deviation

*Indicates significant difference between the mild and severe impairment groups $(p<0.05)$

'Indicates significant difference between the moderate and severe impairment groups $(p<0.05)$

\section{Discussion}

Parkinson's disease is usually associated with the aging process, since the manifestation of signs and symptoms is associated with an $85-90 \%$ decrease of the dopamine concentration at the base ganglia(17). Therefore, the disease initiates long before its symptoms, the manifestations of which can be felt after 60-65 years of age ${ }^{(15,18)}$. The study individuals felt the first signs and symptoms of the disease at approximately 60 years of age, and this could be one of the reasons to explain the delay/difficulty in establishing the diagnosis, considering that this stage of life concentrates manifestation of a great variety of chronic diseases. The majority of the individuals in this study were male, though the literature indicates no difference for incidence of the disease between the genders ${ }^{(18)}$. However, a tendency of higher impairment among men has been registered ${ }^{(1-5,15,18)}$, which is probably more related to cultural aspects. In India, for example, where a higher number of men were recorded among PD patients, the authors themselves attributed the fact to social and cultural contexts which prevent women from seeking health services(18).

In the present study, the higher proportion of men also appears to be a cultural matter associated with the site where the participants were enrolled - the Association. In such places, it is possible that the patients have been registered by members of the family, without necessarily participating in its activities. This kind of behavior matches the Brazilian pattern, since it is culturally accepted that the woman takes the responsibility for taking care of sick family members. This assumed responsibility makes them seek resources to aid the development of such care ${ }^{(19-20)}$. Therefore, a considerable proportion of the male PD patients may have been enrolled by their wives. 
The men presented greater time of disease progress, higher degree of impairment and worse perception of quality of life than the women, though there were no significant differences between the groups. The men were more affected in relation to $A D L$ and social support, while the women were more affected regarding the emotions and bodily discomfort dimensions. These results are also consistent with the role of women in the Brazilian culture, since, although it is common that they take the responsibility when a member of the family gets sick ${ }^{(21)}$, when it is them who need medical care, they hardly ever receive adequate support, and this makes them emotionally fragile. It is interesting to observe that although women presented lower mean scores of disease impairment, they have worse perceptions of bodily discomfort, which can be related to the fact that they continue to perform their home tasks.

Regarding the group of men, it is worth noting their lower ability to handle limitations, pain, and lack of support. Furthermore, the fact that they usually conduct their activities outside the home, thus presenting limited skills for the performance of home tasks, may make them feel limited in general. Regarding the women, despite the reduction of the performance rhythm, they continue doing their usual activities. The simple fact that they keep developing activities related to housework allows them greater mobility for $\mathrm{ADL}^{(22)}$.

The impairment of the QoL happens very early, which can demonstrate a decrease in the first stages of the disease and worsen as severity increases ${ }^{(5)}$. This fact was not found in this study, since, generally, no significant differences were observed between the values of the PDQ-39 and the degrees of impairment of the disease. Only the mobility dimension presented a difference between the mild and severe impairment groups, which indicates that a large increase in the manifestation of signs and symptoms is necessary for this to reflect in decreased mobility. Also, the activities of daily living and cognition dimensions presented differences between the mild and severe groups, and between the moderate and severe groups, indicating a greater sensitivity of these variables to small changes of signs and symptoms of the PD. It is interesting to observe that the motor symptoms were no longer exclusively considered the important determiners of QoL of the PD patients, but also the nonmotor ones, since the progression of the disease brings new alterations that certainly lead to the impairment of other QoL dimensions. The deterioration starts to be observed in the cognition, bodily discomfort, emotions

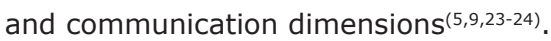

The severity of PD can have a higher impact on the quality of life, within the physical areas, mobility and ADL. However, the psychological adaptation to the disease, measured by indices of cognition, anxiety, depression, self-esteem, acceptance and attitude, is a contributing factor that also impacts directly on the QoL, as well as the severity of the disease(6). Conversely, a low level of psychological adaptation is more relevant than the severity of the disease for a worse QoL from the social perspective(6), since the impairment of motor abilities promotes a decrease in physical independence(2).

In the social dimension, there was no significant difference between the mild, moderate and severe groups. The social support and stigma dimensions can constantly present themselves as the disease progresses, due to the fact that there is an increase in the dissemination of information about PD and support by volunteers and groups $^{(2)}$. A greater impact of the chronic disease on quality of life was reported regarding the aspects of physical ability, activities of daily living and self-esteem ${ }^{(8)}$, however, the social aspects cannot be ignored or be given less importance, because with the increase of the disabilities and limitations of daily living, a stigma can be created that can lead to social isolation.

The majority of the interviewees, 26 individuals, used dopamine, alone or associated with another antiParkinson drug. The dopaminergic drugs also have great influence on the PD patients QoL, considering their complications and adverse effects such as dizziness, motor fluctuations, dyskinesia, depression, among others $^{(22)}$, as well as their contribution to economic impairment. Research has shown that economic expenditure with PD is very high. The costs refer to hospitalization, medication and rehabilitation, as well as domestic costs, productivity loss, reduction of familiar income, and the early retirement of the individual(25).

The low level of schooling of the patients is typical of the level of schooling of most Brazilian elderly ${ }^{(26)}$. Although some authors believe that the low level of schooling can favor the QoL of individuals with PD, given the greater facility to accept the disease(2), we do not agree that access to information can negatively affect living with the disease, since it is progressive and incurable ${ }^{(2)}$. On the contrary, educational and guidance programs are of extreme importance to improve the relationship with the disease, resulting in improvements in the $\mathrm{QOL}^{(25)}$. 


\section{Conclusion}

The results encountered permit a better comprehension of the influence of Parkinson's disease on the quality of life of those who suffer from it, being that a better perception of the quality of life can produce positive effects in the health. Therefore, it is necessary to undertake efforts so that people with PD and their families can better exist with the disease. Thus, the results provide evidence that the performance of health professionals, particularly nurses, should focus on improving the quality of life with the consequent reduction of the impact of the disease. This can be achieved with greater proximity of the professionals, so that the care provided, including guidance and information regarding the disease, its evolution and forms of coping, correspond to the real needs of the patients and their families.

The fact that the men presented more time of evolution of the disease, a higher degree of impairment and a worse perception of the quality of life than the women, as well as greater impairment in relation to ADL and social support, while the women presented more bodily discomfort and had more emotional impairment, indicates the importance of an individualized approach. This approach must take into consideration and valorize, not only the needs presented, but also the important role of the family in the stimulation and socialization of these individuals, including the identification of the needs, potentials and fragilities of the family, for a more effective practice in partnership with them.

Finally, it is worth highlighting that the characteristics of the study sample, its limited size and that it originated from enrollment in an Association that aims to offer support for patients and their families, constitute limitations regarding the results found, which represent only trends that need to be confirmed or refuted. Therefore, further studies are necessary for the verification, or not, of differences between the genders, concerning behavior and disease evolution as well as the perception of quality of life.

\section{References}

1. Rodrigues de Paula F, Teixeira-Salmela LF, Faria CDCM, Brito PR, Cardoso F. Impact of an exercise program on physical, emotional, and social aspects of quality of life of individuals with Parkinson's disease. Mov Disord. $2006 ; 21(8): 1073-7$.
2. Souza RG, Borges V, Silva SMCA, Ferraz HB. Quality of life scale in Parkinson's disease: PDQ-39 (Brazilian Portuguese version) to assess patients with and without levodopa motor fluctuation. Arq Neuropsiquiatr. 2007;65(3-B):787-91.

3. Barbosa MT, Caramelli $P$, Maia DP, Cunningham MCQ, Guerra HLG, Lima-Costa MF. Parkinsonism and Parkinson's disease in the elderly: a communitybased survey in Brazil (The Bambui study). Mov Disord. 2006;21:800-8.

4. A 'Campo LEI, Spliethoff-Kamminga NGA, Roos RAC. An evaluation of the patient education programme for Parkinson's disease in clinical practice. Int J Clin Pract. 2011;65(11):1173-9.

5. Carod-Artal FJ, Vargas AP, Martinez-Martin P. Determinants of quality of life in brazilian patients with Parkinson's Disease. Mov Disord. 2007;22(10):1408-15. 6. Suzukamo Y, Ohbu S, Kondo T, Kohmoto J, Fukuhara S. Psychological Adjustment Has a Greater Effect on Health-Related Quality of Life Than on Severity of Disease in Parkinson's Disease. Mov Disord. 2006;21(6):761-6. 7. Knipe M, Wickremaratchi MM, Wyatt-Haines E, Morris HR, Ben-Shlomo Y. Quality of life in young- compared with late-onset Parkinson's disease. MovDisord. 2011;26(11):2011-8.

8. Martins LM, França APD, Kimura M. Quality of life of people with chronic illness. Rev. Latino-Am. Enfermagem. 1996;4:5-18.

9. Matinez-Martin P, Rodrigues-Blazquez C, Kurtis MM. The impact of non-motor symptoms on health-related quality of patients with Parkinson's disease. Mov Disord. 2011;6(3):399-407.

10. Duncan RP, Earhart GM. Measuring participation in individuals with Parkinson disease: relationships with disease severity, quality of life, and mobility. Disabil Rehabil. 2011;33(15-16):1440-6.

11. Gomez-Esteban JC, Tijero B, Somme J, Ciordia R, Berganzo K, Rouco I, et al. Impact of psychiatric symptoms and sleep disorders on the quality of life of patients with Parkinson's disease. J Neurol. 2011;258(3):494-9.

12. Leroi I, Ahearn DJ, Andrews M, McDonald KR, Byrne EJ, Burns A. Behavioural disorders, disability and quality of life in Parkinson's disease. Age Ageing. 2011;40:614-21. 13. Bucks RS, Cruise KE, Skinner TC, Loftus AM, Barker RA, Thomas MG. Coping processes and health-related quality of life in Parkinson 's disease. J Geriatr Psychiatry. 2011;26:247-55. 
14. Hoehn, MM, Yahr MD. Parkinsonism: onset, progression and mortality. Neurology. 1967;17:427-42. 15. Li H, Zhang M, Chen L, Zhang J, Zhong P, Hu A et al. Nonmotor symptoms are independently associated with impaired heath-related quality of life in Chinese patients with Parkinson's disease. Mov Disord. 2010;25(16):2740-6.

16. Miyashita M, Narita $Y$, Sakamoto A, Kawada N, Akiyama $M$, Kayama $M$ et al. Heath-related quality of life among community-dwelling patients with intractable neurological disease and their caregivers in Japan. Psychiatry Clin Neuroscien. 2011;65:30-8.

17. Lucas-Carrasco R, Pascual-Sedano B, Galán I, Kulisevsky J, Sastre-Garriga J, Gómez-Benito J. Using the WHOQOL-DIS to measure quality of life in persons with physical disabilities caused by neurodegenerative disorders. Neurodegener Dis. 2011;8(4):178-86.

18. Behari M, Srivastava AK, Pandey RM. Quality of life in patients with Parkinson's disease. Parkinsonism Relat Disord. 2005; 11:221-6.

19. Simonetti JP, Ferreira JC. Estratégias de coping desenvolvidas por cuidadores de idosos portadores de doença crônica. Rev Esc Enferm USP. 2008;42(1):19-25. 20. Peters $M$, Fitzpatrick R, Doll H, Playford $D$, Jenkinson C. Does self-reported well-being of patients with Parkinson's disease influence caregiver strain and quality of life? Parkinsonism Related Disord. 2011;17(5):348-52. 21. Schestatsky $P$, Zanatto VC, Margis R, Chachamovitch E, Reche M, Batista G, et al. Quality of life in a Brazilian sample of patients with Parkinson's disease and their caregivers. Rev Bras Psiquiatr. 2006;28(3):209-11.

22. Gómez-Esteban JC, Zarranz JJ, Lezcano E, Tijero B, Luna $A$, Velasco $F$, et al. Influence of motor symptoms upon the quality of life of patients with Parkinson's disease. Eur Neurol. 2007;57:161-5.

23. Grosset D, Taurah L, Burn DJ, MacMahon D, Forbes A, Turner $\mathrm{K}$, et al. A multicentre longitudinal observational study of changes in self reported health status in people with Parkinson's disease left untreated at diagnosis. J Neurol Neurosurg Psychiatry. 2007;78:465-9.

24. Schrag A, Hovris A, Morley D, Quinn N, Jahanshahi $M$. Caregiver-burden in parkinson's disease is closely associated with psychiatric symptoms, falls, and disability. Parkinsonism Relat Disord. 2006;12:35-41.

25. Dowding $\mathrm{CH}$, Shenton $\mathrm{CL}$, Salek SS. A Review of the health-related quality of life and economic impact of Parkinson's Disease. Drugs Aging. 2006;23(9):693-721. 26. IBGE. Pesquisa Nacional por Amostra de Domicílios (PNAD), 2007. [acesso 20 nov 2008]. Disponivel em: http://www.ibge.gov.br/home/estatistica/populacao/ 